Muñiz Oller, M. B. Seguridad urbana y control social: riesgo y criminología actuarial. Derecho y Ciencias Sociales. Mayo- Octubre 2019 N $^{\circ}$ 21. (Derecho, ciudad y propiedad) Pgs 145-165. ISNN 1852-2971. Instituto de Cultura Jurídica y Maestría en Sociología Jurídica. FCJ y S. UNLP

\title{
Seguridad urbana y control social: riesgo y criminología actuarial
}

Urban security and social control: risk and actuarial criminology

\section{María Belén Muñiz Oller}

\section{Resumen}

Tras realizar un breve recorrido por el surgimiento y esparcimiento de la criminología administrativa y sus lógicas actuariales -en el ámbito anglosajón y de Europa continental-, el presente artículo busca reflexionar sobre las consecuencias de su instalación en la gestión de la seguridad. Puntualmente, se hará hincapié en los efectos de la detección del riesgo y las técnicas de prevención en la configuración del espacio y sus formas de habitarlo. En suma, se busca desentrañar de manera exploratoria cuáles son las transformaciones y reconfiguraciones del espacio producidas por la criminología administrativa y su lógica actuarial, a través de la utilización del método genealógico y el análisis de fuentes secundarias.

Palabras clave: seguridad, urbano, riesgo, prevención, actuarialismo

\begin{abstract}
After a brief tour of the emergence and spread of administrative criminology and its actuarial logic - in Canada, United States and continental Europe - this article seeks to analyze the consequences of its installation in security management. Specifically, emphasis will be placed on the effects of risk detection and prevention techniques on the configuration of space and its ways of habiting it. Definitely, it seeks to unravel what are the transformations and reconfigurations of space produced by administrative criminology and its actuarial logic.
\end{abstract}

Keywords: security, urban, risk, prevention, actuarialism

\footnotetext{
- Licenciada en Sociología por la Universidad Nacional de Mar del Plata. Estudiante avanzada del Máster en Criminología, Política Criminal y Sociología Jurídico-Penal de la Universidad de Barcelona. Investigadora en el grupo "Crítica Penal" de la Facultad de Derecho de la Universidad Nacional de Mar del Plata. belumuniz@hotmail.com
}

Recibido: 1/3/2019. Publicable con correcciones: 8/6/2019. 


\section{Seguridad urbana y control social: riesgo y criminología actuarial}

María Belén Muñiz Oller

\section{Introducción}

Es fundamental a la hora de describir y reflexionar críticamente respecto a la gestión del espacio público, analizar las características contextuales en el que se desarrolla; las cuales, al mismo tiempo, nos dan claves para comprender su fundamento. Por ello, comenzaremos resaltando, de forma somera, la influencia de la penología neoliberal (O’Malley, 2006) en la gestión de la seguridad. Nos interesa centrarnos en caracterizarlo en tanto gobierno de "lo social"; esto es, como un modo de organización de la vida en común. Entenderlo de este modo, es comprender la dimensión simbólica que acarrea como modelo económico, político y social. Tener en cuenta esta vertiente, implica tornar observable que dicho modelo no interviene de manera exclusiva sobre el mercado sino sobre "lo social para el mercado" (García y Ávila, 2015:16), impregnando espacios, subjetividades y relaciones sociales desde sus ejes fundantes: la libertad individual y la competencia. Ello en detrimento, claro está, de la autonomía, lo comunitario, los vínculos cooperativos e igualitarios. Se trata de tener en cuenta la dimensión neoliberal que no privatiza o externaliza sólo los recursos públicos sino toda vida en común; no busca eliminar las disfuncionalidades sino detectarlas y contenerlas dentro de un límite tolerable, un desequilibrio sostenible.

Bajo esta dimensión, es dónde se desarrolla y realimenta el dispositivo securitario como parte constitutiva de la indisoluble triada: seguridad-riesgo-neoliberalismo. Aludimos a una forma de gestionar la seguridad que representa la impregnación de los conceptos de riesgo y seguridad en todos los ámbitos de la vida. El mismo se encuentra formado por "policías, vigilantes de seguridad privada y cámaras de video vigilancia, pero también por leyes más duras, arquitecturas preventivas, discursos mediáticos criminalizadores, imaginarios ciudadanos competitivos y prácticas vecinales de desconfianza" (García y Ávila, 2015:19), elementos que integran una forma específica y contemporánea de entender la seguridad. De esta manera, el dispositivo securitario queda así precisado como una tecnología de poder que se encuentra en el centro de las relaciones y las subjetividades. Se lo puede definir, como un hacer en torno al cual se da forma a lo social, un ejercicio de gobernar en el sentido de establecer la forma en que hay que estructurar los comportamientos y las acciones. 
En línea con lo antedicho, en la actualidad nos encontramos con un nuevo paradigma de la seguridad, según Baratta (2001): el modelo de derecho a la seguridad (en contraposición al de seguridad de los derechos), ante el cual, en las ciencias sociales y en las racionalidades públicas se van afirmando formas gerencialistas de pensar la seguridad y la respuesta pública a la delincuencia (Brandariz García, 2014). Nuevas nociones han surgido de este paradigma, entre ellas: la seguridad ciudadana, la prevención situacional, la prevención socio-comunitaria, la policía de proximidad, alerta comunitaria, etc. Estas nociones se relacionan con otros conceptos como: el pánico social, la indignación social, la sensación de inseguridad, la defensa social, la cuestión ético-política del merecimiento, etc. De esta forma, lo que David Garland (2005) diagnostica como fin del welfarismo penal -caracterizado por el análisis de las causas psicosociales del delito y por los principios de las ideologías "re" (re-habilitación, reintegración, re-inserción, re-socialización, re-educación) del delincuente-, encontró como sucesora una nueva criminología más centrada en el análisis de las oportunidades para el hecho delictivo y el control de las mismas. Esta nueva criminología, sin embargo, tomó dos caminos distintos: por un lado proliferó una criminología del sí mismo que, apoyándose en herramientas técnicas, promovía la prevención de la delincuencia basándose en el análisis de los factores ambientales y situacionales, y por otro, una criminología del otro ligada a la justicia expresiva y el populismo punitivo, que hace del enemigo social de turno (ladrón, violador, pederasta, inmigrante, etc.) el depositario de los deseos de venganza (Brandariz García, 2014; García y Ávila, 2015). En el presente artículo nos centraremos en la criminología del sí con la intención de analizar cómo sus características repercuten en la configuración del espacio social urbano. Lo siguiente, se llevará a cabo de manera exploratoria a través del método genealógico ${ }^{1}$ (Ewald, 1984), el cual consiste en rastrear el pasado con intención analítica pero no archivística, de manera que se realice una historia del presente. La razón para usar esta orientación metodológica es realizar un análisis que no caiga en el a-historicismo ya que nos permite conocer cómo se problematizan los fenómenos sociales dependiendo del contexto social y la hegemonía cultural. Esto es, buscamos no tomar como dados a los sucesos del presente sino cuestionar su "normalidad", analizando su desarrollo histórico y la manera en que se han legitimado las instituciones y discursos del pasado. Según Robert Castel es aplicable al campo de la sociología para no construir un discurso que se aleje de la construcción histórica de los problemas sociales (Castel, 2005).

\footnotetext{
${ }^{1}$ Esta metodología es la propia de los trabajos filosóficos de Michel Foucault, aunque su precedente son las obras de Friedrich Nietzsche, centralmente su obra "Genealogía de la moral", la cual consiste en la búsqueda del origen de la moral, saber cuándo y porqué se había definido qué era lo ontológicamente bueno o malo en la intención de cuestionar la moral cristiana.
} 


\section{"Criminología del sí mismo" o administrativa: surgimiento y técnicas}

Siguiendo a Brandariz García, el actuarialismo es un concepto de muy difícil clasificación siendo que no conforma una escuela teórica o una tecnología punitiva con precisiones bien delimitadas. Esto mismo, puede deberse sobre todo a que las teorizaciones sobre el actuarialismo han sido realizadas más por sus críticos que por sus defensores y practicantes. De todas maneras, intentaremos en lo que sigue, articular todas las definiciones y principales características que sustentan y rodean a dicho concepto. A modo de adelanto, delimitaremos nuestro objeto de estudio entendiéndolo como un conjunto articulado de orientaciones políticocriminales y prácticas punitivas (Brandariz García, 2014), como una forma común de conceptualizar cuestiones, como una forma estratégica de saber-poder (Feeley y Simon, 1995). El paradigma actuarial o new penology, corresponde a una racionalidad penal de gestión de riesgos que ha intervenido en la política criminal, la criminología y la penología, extendiéndose rápidamente por el mundo occidental a finales del siglo XX.

Hace ya más de 25 años Feeley y Simon (1995) impusieron el término "actuarialismo" para dar coherencia a una serie de modificaciones que observaban que estaba sufriendo el ámbito penal. Para referirse a dichas transformaciones, en literatura se utilizan conceptos genéricos como nueva penología, criminología actuarial, justicia actuarial, lógica actuarial, modelo gerencialactuarial de penalidad o políticas criminales actuariales, que engloban todo un conjunto de transformaciones producidas en el sistema penal (Domínguez Figueirido y Rodríguez Basanta, 2003). A su vez, diferentes conceptualizaciones dan cuenta de las transformaciones acaecidas por el actuarialismo en la criminología y las políticas penales como lo son: "criminología del sí mismo", "criminología administrativa”, criminologías de la vida cotidiana, incivilities, etc.

Una de las definiciones más estrictas y abarcativas que permiten adelantar los rasgos básicos del concepto es la de Harcourt, quién señala que el actuarialismo penal se trata de una tendencia caracterizada por

El uso de métodos estadísticos, en vez de clínicos, consistentes en amplias bases de datos, para determinar los diferentes niveles de actuación criminal relacionados con uno o más rasgos grupales, a los efectos (1) de predecir la conducta criminal pasada, presente o futura, y (2) de administrar una solución político criminal. (Harcourt, 2007:1)

En otras palabras, es un modelo securitario sustentado en un paradigma eficientista, impulsado por el gerencialismo y el actuarialismo y orientado por una matriz economicista de coste- 
beneficio, que resulta ajena a la racionalidad jurídica. Sus lógicas de funcionamiento, sus parámetros de legitimación y sus criterios de validación se rigen por la objetividad, la eficiencia y la utilidad preventiva. De lo anterior se desprende que el objetivo es perfilar medidas que neutralicen el riesgo (Lea, 2004) confiando en la capacidad predictiva de los métodos estadísticos (Logan, 2000). En definitiva, lo que busca esta política de gestión de riesgos es reducir los costes para combatir el delito y mantener unos niveles de delincuencia admisibles y tolerables (Brandariz García, 2014). No se busca descubrir la culpabilidad ni rehabilitar al infractor sino regular los niveles de riesgo. Su derecho penal no busca proteger los derechos del infractor frente al estado, sino agrupar y clasificar adecuadamente a los potenciales sujetos peligrosos (Gutiérrez, 2008).

\section{Breves reflexiones acerca de los orígenes y expansión de la criminología administrativa}

Está claro que la búsqueda de orígenes y surgimientos es un tanto infructuosa si pensamos que nada surge sin una relación precedente, sin antecedentes, sin historia. Cuando hablamos del surgimiento del actuarialismo debemos remontarnos a un contexto con presente y pasado dónde la Escuela Clásica y el positivismo criminológico son antecesores fundantes de la lógica actuarial.

En este sentido, es importante no perder de vista la literatura que ha enfatizado que la racionalidad de gestión de riesgos no es algo propiamente nuevo en materia político-criminal, del mismo modo que no lo es la preocupación por la peligrosidad de los infractores (Hudson, 2003; Pratt, 2000). Sin duda, existen antecedentes de las bases fundacionales de la criminología en la gestión del riesgo. Sin embargo, y sin perjuicio de lo atinado de este planteamiento, ha podido afirmarse que el actuarialismo penal supone la apertura de un tiempo postmoderno en materia político-criminal (Brandariz García, 2014). Fundamentalmente, en la medida en que incorpora elementos diferenciales en la gestión punitiva del riesgo en relación con aquellos antecedentes. Así, la literatura académica que ha abordado la genealogía de los planteamientos actuariales, sostiene que lo innovador del contexto presente son las lógicas y técnicas para evaluar y afrontar el riesgo más que la atención al riesgo criminal en sí misma.

En lo que sigue, nos adentraremos por tanto en el surgimiento de la lógica actuarial en tanto nueva racionalidad penal, que ha provocado sustanciosos cambios en materia política-criminal e incluso un cambio de paradigma.

\section{Factores de incidencia en el surgimiento del modelo actuarial gerencial en la penalidad}


Del mismo modo que las definiciones del actuarialismo son de difícil clasificación, el surgimiento del mismo también es impreciso. Pese a ello, en lo que sigue, realizaremos un somero recorrido por todas las influencias que conllevaron al surgimiento del actuarialismo en su fase post-moderna.

A la hora de buscar antecedentes próximos, la referencia más oportuna según Brandariz García (2014), serían informes ${ }^{2}$ que propugnaron el giro gerencial-actuarial en la penalidad, en el contexto anglosajón a comienzos de los años 80. Asimismo, la irrupción de esta racionalidad punitiva suele ser identificada a partir de las tendencias norteamericanas propias de la llamada neutralización selectiva -surgidas a finales de la década de 1970- que pretendía agrupar infractores según niveles de riesgo delictivo $\mathrm{y}$, de esta forma, dilucidar a quienes les correspondía recibir mayor penalidad. Sin embargo, lo cierto es que, la reorganización de la política criminal a partir de la prioridad teleológica de la gestión de riesgos fue puesta de manifiesto de manera seminal por los trabajos de Feeley y Simon de la década del 90, en los cuales la denominaron como la "Nueva Penología".

A partir de estos antecedentes y con la intención de aproximarnos a un contexto cultural y político de influencia, Rivera Beiras y Lazo (2005) indican que el actuarialismo se ha configurado y expandido desde los ochenta, pero adquiere visibilidad y centralidad en la década de los noventa en el ámbito anglosajón y Europa continental. De todas formas, si ahondamos un poco más, existen ciertos factores que fueron de rotunda influencia en lo que a la expansión y consolidación del modelo gerencial-actuarial refiere.

En primer lugar, el término "actuarial" proviene del campo de las grandes aseguradoras. Mientras estas compañías convertían un peligro abstracto en dinero, el actuarialismo a partir de un catálogo de posibles riesgos posibilitaba su gestión y prevención, ahorrando dinero. De hecho, la palabra "actuarialismo" proviene realmente de la labor del "actuario". El mismo consistía en catalogar riesgos frente a determinadas circunstancias dentro de una compañía de seguros, por ejemplo, asegurar los riesgos de conducir un auto (Rivera Beiras, 2015; Brandariz García, 2014).

En segundo lugar, la afirmación del riesgo como criterio de comprensión de la vida colectiva y principio organizador básico de las políticas públicas, ha ido cobrando a partir de la década del 70 una innegable influencia en materia político-criminal. Está claro, que, si observamos la fortaleza del actuarialismo en relación a la influencia de la gestión del riesgo en las políticas penales, el paradigma actuarial se suele vincular también con el surgimiento de una "sociedad

\footnotetext{
${ }^{2}$ Los informes de Floud y Young (1981) y de Greenwood (1982).
} 
del riesgo" (Beck, 1998). Ante las complejidades de las sociedades modernas, los riesgos son cada vez más diversos e inabarcables. Las crisis económicas, ambientales, nucleares, entregan un sentimiento de inseguridad a los ciudadanos y la idea de que el Estado ya no puede hacer frente a dichas problemáticas. De esta forma, el responsable de asegurarse ante estos nuevos riesgos y nuevas criminalidades es el propio individuo -dada la ruptura del tejido social y la asunción del mercado como regente de todos los aspectos de la vida- que comienza a obsesionarse con la idea de seguridad (Rivera Beiras y Lazo, 2005). Así, al ser imposible controlar todos los riesgos a los que se ven expuestos los individuos y la sociedad entera, estos deben ser "gestionados". De todas formas, es preciso aclarar que la conexión entre el actuarialismo y la teoría de la sociedad del riesgo de Beck solo se sostuvo, por parte de la literatura, a finales de los años 90. Desde entonces, parece bastante claro que el actuarialismo se ha construido sobre otras perspectivas en relación con el riesgo, fundamentalmente la genealógica y la cultural.

En tercer lugar, el actuarialismo no es únicamente una tecnología de gestión en el marco de una sociedad donde el riesgo permea cada aspecto de la vida social, sino que "es una nueva racionalidad penal fruto del auge del neoconservadurismo o de la nueva derecha en los países occidentales -sobre todo en los anglosajones" (Rivera Beiras y Lazo, 2005:233). Esta "nueva penología" surgiría en vinculación con un declive en el ideal rehabilitador; esto es, entre el cruce de las promesas populistas de las elites políticas sobre "encerrar a los delincuentes" y la necesidad de traducir esta demanda política en técnicas administrativas para las agencias como la policía o la cárcel (Gutiérrez, 2008). De esta forma, el actuarialismo se consolida con la perspectiva de la eficacia y eficiencia que el modelo centenario de las ideologías "re" no pudo suplir. Como hemos visto en la sección precedente, estas ideologías de la resocialización, repersonalización, reeducación, reinserción perciben un declive a fines de la década del ochenta, tras una paulatina liquidación de la cultura del welfare, la desconfianza en la eficiencia de las ideologías "re" (el famoso "nothings works"), la consagración de políticas criminales altamente represivas, y la paulatina construcción de la criminología de la intolerancia, entre otras causas. Podríamos conjeturar, en una primera aproximación, que ante un Estado de bienestar en declive que dejaba población marginal, y ante un correccionalismo e ideal rehabilitador que dejaba entrever ineficacia (reincidencia en la población carcelaria) se necesitaba de manera urgente el control para devolver equilibrio al orden social (y sus relaciones de poder).

\section{Criminología administrativa o actuarial}


Con respecto a la criminología, sí la entendemos como aquel componente de las ciencias penales que se centra en las causas del delito, la criminología actuarial o administrativa se centraría en regular a "límites tolerables" el delito y no a erradicarlo (Gutiérrez, 2008:2). Por lo tanto, desde el ámbito criminológico -de la misma manera que desde el de la política criminal"el objetivo de la justicia actuarial es el manejo de grupos poblacionales clasificados e identificados previamente como peligrosos y riesgosos" (Rivera Beiras, 2015:106). Ejemplo de esta identificación se vuelve la prevención situacional y la criminología ambiental. Ante las cuales, las causas y razones del delito no interesan, ni la rehabilitación del victimario, sino que lo que preocupa son "las circunstancias en las que se delinque y en reducir las oportunidades para el delito" (Summers, 2009:396). Se asume, por lo tanto, una visión racional y de tonalidad economicista en el comportamiento "libre" y "responsable" del individuo, que a la vez está basada en la ponderación de los costos y beneficios acoplados a la decisión de cometer infracciones delictivas. Siguiendo a Fraile y Bonastra, esta criminología actuarial "soslaya el diseño de aquellas estrategias que cabría dirigir al núcleo del problema siendo que su objetivo es colocar la eventualidad calculada de la contravención dentro de unos márgenes asumibles socialmente" (2015:306).

Es importante aclarar en este punto que, y siguiendo a Máximo Sozzo (2000), se pueden distinguir al menos tres tácticas alternativas de prevención del delito en los diversos horizontes culturales que atraviesa el debate internacional: la táctica situacional y ambiental, la táctica social y la táctica comunitaria (Pavarini, 1994; Creazzo, 1996; Baratta, 1997; Crawford, 1998). Debido a la extensión del presente artículo y su carácter exploratorio haremos hincapié en la primera táctica: la situacional y ambiental. Entre otras cuestiones, porque es a través de la táctica situacional y ambiental que el actuarialismo es el ámbito dominante de la criminología actual. La teoría de la oportunidad, el crime mapping o las ordenanzas civiles/cívicas son ejemplo de esta gestión de la seguridad a los que haremos referencia en lo que sigue. Se prestará especial atención al concepto clave que orienta dichas políticas, el de prevención, tratando de dar cuenta de cómo ha sido resignificado -de apelar a las causas estructurales de la inseguridad, el concepto ha pasado a significar las condiciones situacionales y oportunistas para la transgresión- y refuncionalizado -de operar como un igualador entre grupos sociales, la prevención ha pasado a funcionar como un reproductor de la segregación urbana (García y Ávila, 2015).

\section{Prevención del delito: táctica situacional y ambiental}


Esta táctica surgió en los primeros años 80 en los Países Bajos y en diversos contextos del mundo anglosajón: Estados Unidos, Australia y Gran Bretaña, especialmente impulsada por las agencias estatales encargadas del diseño de las políticas de control del crimen (Creazzo, 1996). La emergencia de la táctica situacional y ambiental coincidió en buena parte con la instalación de gobiernos comprometidos con racionalidades políticas neoliberales, que enfatizaban el mercado libre, el estado mínimo y la libre elección y responsabilidad individuales (O’Malley, 1992; Crawford, 1998), como analizábamos en el primer apartado. Asimismo, y como también fue mencionado, esta táctica promovía visiones del delito que compartían presuposiciones básicas de lo que Garland ha denominado las “criminologías de la vida cotidiana” las cuales

Observan al delito como una continuación de la interacción social normal, explicable por referencia a patrones motivacionales standard. El delito se transforma en un riesgo que debe ser calculado (tanto por el infractor como por la potencial víctima) o un accidente que debe ser evitado, más que una aberración moral que necesite ser explicada. (Garland, 2005:450-452)

El objetivo central de esta táctica de prevención del delito puede ser sintetizado como la reducción de oportunidades para la realización de los delitos. Las teorías de la oportunidad fueron desarrolladas por Felson y Clarke, siendo su principal idea, que el comportamiento individual es producto de la interacción entre la persona y el entorno físico. Según estas teorías, los escenarios hacen que se unifiquen las inclinaciones punibles del individuo con acciones delictivas favorecidas por escenarios que ofrecen más oportunidades y tentaciones delictivas (Felson y Clarke, 2008). Por lo cual, todas estas teorías, pese a sus diferencias, se centran en la prevención con el objetivo de evitar el delito mediante la alteración de la oportunidad y tentaciones.

El éxito de esta táctica depende de la posibilidad de que los potenciales ofensores sean efectivamente afectados por las intervenciones sobre la situación y el ambiente, de manera tal que perciban a estos elementos como influencias adversas con respecto a la facilidad, el riesgo o las recompensas de la realización de los delitos. (Sozzo, 2000:7)

De este modo, las técnicas de prevención situacional están enfocadas en alguno de los elementos que forman la química del delito, por lo cual, si se consigue influir en ellas, se entiende que las oportunidades delictivas se verán limitadas.

La tabla que sigue será más ilustrativa para mostrar estas técnicas: 
Tabla 1. Clasificación de las técnicas de prevención situacional.

\begin{tabular}{|l|l|}
\hline 1. Aumentar el esfuerzo de la comisión & - Control de accesos \\
del delito & - Control de salidas \\
& - Entorpecer objetivos \\
\hline $\begin{array}{l}\text { 2. Aumentar el riesgo al que se somete } \\
\text { el infractor a la hora de cometer el }\end{array}$ & guardianes \\
delito & - Facilitar la vigilancia \\
\hline $\begin{array}{l}\text { 3. Disminuir las ganancias que el } \\
\text { infractor puede obtener a partir de la }\end{array}$ & - Ocultar objetivos \\
actividad delictiva & - Eliminar beneficios \\
\hline 4. Reducir las provocaciones, es decir, & - Reducir frustraciones \\
evitar la exposición de objetos al & - Neutralizar la presión de los \\
público & grupos \\
\hline 5. Eliminar excusas & - Disuadir de las imitaciones \\
\hline
\end{tabular}

Fuente: elaboración propia basada en Summers (2009:398).

Asimismo, estas tácticas pueden orientarse a evitar que las personas sean víctima de delitos, además de a reducir las posibilidades del mismo. Me refiero aquí al "enfoque bidimensional" (Pavarini, 1994).

Existen un conjunto de hipótesis teóricas que subyacen a las técnicas de intervención y que Crawford ha intentado aislar, a saber:

Una creencia en que los aspectos situacionales son más susceptibles de transformarse que cualquier otro que pueda influenciar el delito y por lo tanto constituir los blancos más apropiados de las políticas públicas; una asunción de que buena parte de los delitos son oportunistas; una creencia en el papel de la elección humana en la acción criminal, en función de un modelo de elección racional del comportamiento humano; una promoción de la disuasión, con un énfasis relativo en la certeza de la detección más que en la severidad del castigo. (1998:69) 
Las fuentes de estas hipótesis teóricas, según Crawford (1998), son tres: teoría de la elección racional, "Designing out crime" y teoría de las actividades rutinarias (Felson y Clarke, 2008; Crawford, 1998; O’Malley, 1992; Pavarini, 1994).

También, con ánimo de reforzar aún más los argumentos expuestos anteriormente, quisiéramos mencionar alguna tendencia actual relativa a la predicción del delito. Tendencia que sigue la lógica actuarial de la que venimos hablando: el crime mapping. Actualmente, los avances tecnológicos han facilitado el procesamiento rápido y preciso de los datos, lo cual ha favorecido el uso y la evolución de los mapas de criminalidad (Segato, 2007). Se trata de localizar geográficamente el delito mediante los mapas, es un instrumento que se utiliza para gestionar y relacionar el delito con los datos geográficos, representándolos mediante una imagen en forma de mapa de dos o tres dimensiones. Este mapa ofrece diversas informaciones para sus receptores sobre la relación entre las variables delito y espacio, ante la cual cabe la predicción del delito.

Tal vez el tema central del debate en estos marcos conceptuales es hasta qué punto la situación o el ambiente puede ser visualizado como un generador del delito -como lo hace, en cierto sentido, la perspectiva del "designing out crime"- o debe ser concebido como un receptor de dichos problemas. Está claro, que es un debate irresuelto teórica y empíricamente en estas tradiciones y a su vez excede el propósito del presente trabajo. Pero sí es importante dimensionar, que cada una de las teorías considera que la oportunidad para delinquir es un generador de delitos, por lo cual, explican que la alteración del número de oportunidades delictivas en cualquiera de los ámbitos produce un cambio en el resultado del delito. Asimismo, que lo que se demuestra como un común denominador es la visión del delito como

Un aspecto normal, un lugar común de la vida moderna. Es un evento - o, mejor dicho, una masa de eventos - que no requiere una motivación o disposición especial, ni una patología o anormalidad y está inscripto en las rutinas de la vida económica y social contemporánea. (Garland, 2005:450)

\section{Ordenanzas cívicas como ejemplo}

Si dirigimos la mirada hacia las políticas securitarias centradas en los pequeños delitos e incivismos de la vida cotidiana local, observaremos cómo, además de discursos neoconservadores, comienzan a desplegar sus alas políticas de seguridad ciudadana netamente gerenciales (García y Ávila, 2015). 
Fiel a las ideas actuarialistas, el incivismo se entiende como un problema a solucionar que afecta principalmente a la ciudadanía. Pero este problema podemos decir que no es consecuencia de estas medidas, sino que:

El incivismo apareció como un marco interpretativo que permitía construir un estado negativo de cosas en el espacio público, permitiendo justificar la ideación y aplicación de una serie de medidas que, con el aspecto de una solución, harían viables fórmulas más intensas y extensas de regulación formal de la convivencia. (OSPDH, 2009:35)

Así, muy influenciado por esta prevención situacional, diferentes ciudades españolas han ido tomando en las dos últimas décadas medidas orientadas a erradicar conductas incívicas que suponen un peligro para el resto de la ciudadanía. Un ejemplo de estos lugares ha sido y es la ciudad de Barcelona, la cual mediante sus diferentes ordenanzas civiles ha sido objeto de duras críticas. Especial atención merece en este caso l'Ordenança de mesures per fomentar i garantir la convivència ciutadana a l'espai públic de Barcelona (la Ordenanza de medidas para fomentar y garantizar la convivencia ciudadana en el espacio público de Barcelona) la cual entró en vigor el 25 de enero de 2016 (OSPDH, 2009:7).

El Observatorio del Sistema Penal y los Derechos Humanos (OSPDH) realizó en el año 2009 una investigación que analizaba los primeros indicios de políticas públicas basadas en la criminología administrativa en Barcelona, las cuales entraron con fuerza gracias a la Ordenanza de 2006, ordenanza que tenía y actualmente tiene el único fin de "conseguir la defensa de los derechos de los ciudadanos persiguiendo y sancionando aquellas actividades que generen un malestar o incomodidad” (Arella, Fernández Bessa, Lazo y Vartabedian, 2005:4).

Tras un detallado recorrido por las medidas, aplicación y jurisprudencia de esta Ordenanza, enumeran sus consecuencias tanto jurídicas, como sociales y espaciales. Como consecuencias jurídicas para la persona, se detienen en la ambigüedad e inseguridad jurídica, en la vulneración de las garantías procesales, en las posibles extralimitaciones en la aplicación de las sanciones y en la ampliación de la judicialización penal de las relaciones sociales. En tanto consecuencias sociales, detectan el incremento de las situaciones de vulnerabilidad, el incremento y legitimación del rechazo social hacia determinados colectivos: estigmatización y los obstáculos a la expresión y participación ciudadana. Por último y en lo que respecta a las consecuencias espaciales hacen referencia a, por un lado, 
El impacto "locacional" que la aplicación de medidas de prevención y sanción del incivismo tiene sobre la ocurrencia, censura y desplazamiento de comportamientos en el espacio urbano. Por otra parte, estas medidas y la racionalidad en la que se sustentan han repercutido sobre la construcción normativa y el significado del espacio público como entorno de relaciones sociales. (OSPDH, 2009:143).

Siguiendo con el informe del Observatorio, los autores hacen referencia a como el discurso y la censura del incivismo han establecido una nueva "geografía moral" (Sibley, 1995). Esto significa que el carácter (in)aceptable, (in)correcto o (in)admisible de ciertos comportamientos en el espacio público viene dado exclusivamente, por el lugar específico donde se producen (OSPDH, 2009). Un ejemplo que mencionan en el informe que confirma la existencia de una nueva geografía moral, es que beber alcohol en las escaleras de la plaza del Sol de Gracia (barrio de la ciudad de Barcelona) es un acto incívico, y por tanto sancionable, mientras que hacer lo mismo en la terraza situada a escasos dos metros de aquellas escaleras es una conducta aceptada. Asimismo, otro punto relevante que mencionan es la intervención combinada de los agentes policiales y los servicios de limpieza quienes entre las dos y las cuatro de la madrugada desalojan las plazas pidiéndoles a las personas que se vayan porque hay que "limpiar la plaza". Una fórmula de vaciamiento del espacio público a través de la retórica de la limpieza.

\section{Repercusiones de las técnicas situacionales y ambientales en el espacio social}

Con ánimo de reflexionar acerca de las repercusiones que las tácticas mencionadas provocan en el espacio social, es dable comenzar por explicitar qué se entiende por espacio social.

El espacio social es una construcción; un espacio que se sobreconstruye en la contradicción de la apropiación individual de una producción colectiva (Nuñez, 2006). Se trata de considerar el carácter social del espacio en tanto es producción de condiciones materiales y sociales de existencia, apropiación y expropiación de esas condiciones.

En diálogo con Henri Lefebvre (1973, 1976), el espacio urbano es un producto social, es decir, es el resultado de las acciones, prácticas y relaciones sociales en el territorio, pero a su vez es parte de ellas. En este sentido, el espacio es soporte, pero también es campo de acción. No hay relaciones sociales sin espacio, de igual modo que no hay espacio sin relaciones sociales (Martínez Lorea, 2013). En la producción social del espacio urbano no sólo intervienen las acciones de planificación y regulación; también las distintas formas de habitarlo y experimentarlo hacen posible su producción. Sobre ambos aspectos, considero que uno de los mayores aportes al campo de la sociología urbana ha sido la obra de Lefebvre, ya que se ha 
centrado en la producción de lo urbano, y en particular, el espacio como medio de reproducción de las relaciones de producción y de control social y ejercicio de poder; haciendo del habitar una práctica alienante, que deja de lado las necesidades sociales.

\section{¿Las técnicas situacionales y ambientales ejercen control social? ¿Generan modificaciones en el espacio social?}

En primer lugar, la producción de lo social es ininteligible sin introducir la noción de confrontación, de enfrentamiento, de luchas entre existencias. Así, ese proceso de construcción/destrucción de relaciones sociales no se puede hacer sin utilizar fuerza material (Nuñez, 2006). Pero hay relaciones sociales en las que el uso de esta fuerza material no se ve; la violencia ejercida se mantiene inobservable porque ha sido naturalizada; normalizada, porque uno está situado del lado del poder y el otro del lado de la obediencia.

Así, estas técnicas actuariales que se han venido describiendo ejercen una violencia cotidiana constitutiva del orden social. Siguiendo a García y Ávila (2015), se entiende que el régimen neoliberal retroalimentado por el dispositivo securitario promueve nuevas formas de violencia subsumidas en una cotidianidad estructural y constitutiva del orden social, que atraviesa los cuerpos, que gestiona espacios, que crea hábitos, que segrega y excluye. Nos encontramos con una violencia que, siguiendo a Baratta, "en todas sus formas es represión de las necesidades reales y por tanto violación de los derechos humanos" (1997:446). Así, el dispositivo securitario queda precisado como una tecnología de poder que se encuentra en el centro de las relaciones y las subjetividades. Se lo puede definir, como un hacer en torno al cual se da forma a lo social, un ejercicio de gobernar en el sentido de establecer la forma en que hay que estructurar los comportamientos y las acciones, una forma de violencia que gestiona las desigualdades y controla los riesgos. Nos encontramos, entonces, ante un paradigma que encubre violencias, paradójicamente, alegando como función "la contención de lo violento". Unas violencias que se ubican en el núcleo mismo de una trama narrativa que se lee a sí misma en clave de progreso, de inclusión, de seguridad (Mendiola y Brandariz García, 2015).

Esta violencia que ejerce un dispositivo securitario, enmarcado en un régimen neoliberal, que utiliza tácticas ambientales y situacionales, propias de la lógica actuarial, tiene muchas aristas y dimensiones ante las cuales nos centraremos en las que nos parecen centrales a la hora de analizar las repercusiones en el espacio social.

En los últimos años se ha generado una conciencia colectiva de inseguridad creando una auténtica construcción social de que la vida cotidiana está llena de riesgos. De esta manera, tal como señalan Fraile y Bonastra: 
La ciudad es la construcción social que garantizaba un adecuado equilibrio entre libertad y seguridad; tal guarismo se desequilibró a causa del incremento de la inseguridad asociada a la delincuencia. La ciudad se presenta como un core de la violencia y de la inseguridad, o el ámbito donde los riesgos se materializan. (Fraile y Bonastra, 2011: 9).

Este factor tan estudiado en el ámbito académico-intelectual genera, entre muchas otras consecuencias, estigmatización y desconfianza. Con respecto a la primera consecuencia, y en tanto objeción de orden teórico-conceptual, las tácticas situacionales y ambientales, recuperan conceptos ampliamente superados como el de peligrosidad social, desviación social, conducta antisocial. En el fondo, lo que subyace al modelo comentado, es la noción del carácter antisocial del comportamiento de la persona objeto de detección; carácter fuertemente ligado al concepto de desviación. La categoría de "desviado", de "antisocial" implica entender, entre otras cuestiones, la existencia de individuos que tuvieron "fallas" en los procesos de socialización (en las instituciones sociales como la escuela o la familia) que integran a los individuos dichos valores sociales (Parsons, Merton, Durkheim, etc.). Supone, por tanto, un incremento e instrumentalización de los procesos de selectividad y se basa en el paradigma etiológico de las escuelas positivistas y funcionalistas. Siguiendo a Fraile y Bonastra,

Se suele traducir en un esfuerzo por definir cuáles son los colectivos que los pueden generar, lo que suele ir acompañado de una discriminación selectiva de tales grupos, que se acentúa en el caso que sean fácilmente identificables. (2011:128)

Con respecto a la desconfianza, las técnicas actuariales requieren de una coproducción de la seguridad con la ciudadanía. Lo cual implica una actitud vigilante por parte del ciudadano/a y unos determinados comportamientos preventivos y de cuidado para no convertirse en víctima. Las ordenanzas municipales que hemos visto como ejemplo, ordenan y consignan acciones, pero a su vez comportamientos, que previenen de un conflicto. Se dice cómo se tiene que conducir, qué lugares evitar, qué se ha de controlar, qué se ha de reprimir, cómo defenderse e incluso, cómo debería modificar su entorno físico. Asimismo, tanto la desconfianza como la estigmatización, pueden promover una fe ciega en la tecnología que puede ser injustificada y que está guiada fundamentalmente por intereses comerciales de la creciente industria de la seguridad (alarmas, iluminación, sensores de movimiento, cámaras de video vigilancia, etc.). Lo cual además de generar un evidente control social invasivo, también desplaza el potencial 
de la importancia de la agencia humana en las actividades de control del crimen (Crawford, 1998).

En suma, las técnicas actuariales

Refuerzan la sensación de inseguridad y de desconfianza, a menudo hacia ciertos colectivos estigmatizados, no avanzan en la reflexión sobre las causas y, una vez más, dificultan la puesta en marcha de prácticas de mediación y de incremento de la cohesión social. (Fraile y Bonastra, 2011:129)

Son técnicas que ejercen una violencia que organiza la vida social ocultando sus principales motores: la desigualdad social y la instalación de la lógica del mercado en los espacios y las relaciones sociales. Motores que existen en detrimento de la creación de espacios de confianza desde los que construir autonomía, comunidad e igualdad: asociaciones o centros de vecinos, por ejemplo, que permitan construir lazos comunitarios y solidarios. Relaciones sociales que repercuten en la generación de mayor espacio público, integración y cuidados vecinales que permiten mayor interacción e intercambio en las calles, menos vigilancia y seguridad que permiten menor segregación y exclusión.

En línea con lo anterior, la intervención de esta táctica de prevención del delito sólo ocasiona que el delito escape hacia otro lugar. Lo cual además de visibilizar unos resultados bastante pobres, este desplazamiento geográfico y espacial del delito también genera cambios que conllevan a una segregación de clase: la generación de barrios marginados en la periferia de las ciudades donde se concentra el delito y quienes delinquen (los pobres), generando territorios protegidos y otros desprotegidos. Sobre esto último, tal como señala Pavarini (1994), dicha táctica prioriza exclusivamente los delitos contra la propiedad en los espacios públicos, silenciando en la agenda preventiva los delitos en la esfera privada, particularmente en el hogar (violencia contra las mujeres, violencia contra los niños, etc.) y la criminalidad económica, la criminalidad organizada y los delitos de la autoridad (Baratta, 1997; Creazzo, 1996).

Así, vemos una contundente diferencia de trato promovida por estas técnicas. "La tolerancia cero se aplica especialmente a algunos sujetos, mientras que otros tendrán mayores márgenes de autonomía" (García y Ávila, 2015:16). Esto mismo tiene repercusiones en el espacio público como el denominado "stop and search", esto es, la habilitación legal para exigir la presentación de documentación y sancionar en caso de que no se satisfaga el requerimiento. Una táctica represiva e intimidatoria que se basa en la obligación general de identificarse, de manera no vinculada a la prevención o investigación de un delito en concreto. Está claro, que esta habilitación legal de controlar poblaciones repercute en el espacio, permitiendo la 
autonomía de circulación a unos habitantes más que a otros (el stop and search resulta de especial relevancia en lo que respecta a la represión de los derechos de los migrantes).

Otra cuestión a tener en cuenta es la generación de políticas de seguridad a través de supuestos datos "objetivos". Esto mismo, promueve también la inserción de distintas voces que ejercen presiones (mediáticas, comerciales y vecinales), ya que la visibilidad de estadísticas y cifras de victimización permea la posibilidad de opiniones. Al mismo tiempo que, estos métodos estadísticos facilitan la posibilidad de diseñar intervenciones distintas y objetivos diferenciales para unos distritos y otros. Sobre esto último, los investigadores García y Ávila nos muestran el ejemplo de la ciudad de Madrid donde el distrito 'centro' no es considerado un espacio inseguro por la ciudadanía, sin embargo, su posicionamiento como espacio turístico y comercial conllevan una sobre-presencia policial respecto a los barrios periféricos. Así, "Los datos de geo-referenciación, los sucesos más mediáticos y las demandas y presiones externas a la policía, nuevamente orientarán acciones diferenciales" (García y Ávila, 2015:17).

\section{A modo de cierre}

Hemos realizado un somero repaso por las transformaciones y reconfiguraciones del espacio producidas por la criminología administrativa y su lógica actuarial. Nos acercamos a partir de las mismas, a analizar el modo en que se producen y vivencian los espacios.

Consideramos que lo más importante a resaltar, es que las técnicas de prevención traen consecuencias de segregación y exclusión espacial donde habitar se contrapone a la configuración de lazos comunitarios y se plasma paulatinamente un predominio de "lo privado" por sobre "lo público", la lógica del mercado por sobre la lógica de lo social, las relaciones de competencia por sobre las relaciones de confianza.

El presente artículo no es más que una aproximación exploratoria de un fenómeno en crecimiento en un contexto global. El riesgo, desde un punto de vista genealógico, constituye en la actualidad el principio organizador de la criminalidad y la respuesta punitiva al delito. Por tanto, nos parece fundamental profundizar líneas de investigación que comienzan a contrastar investigaciones que se centren en analizar casos concretos respecto al objeto de estudio.

Respecto a esta temática se abren múltiples interrogantes y posibles líneas investigativas En un mundo cada vez más globalizado, la incidencia o construcción de riesgos parece ser inherente a la actualidad y, ante su "imposible resolución", asistimos a un descrecimiento de los EstadoNación. Dicho descreimiento junto con el desmoronamiento del modelo correccional -del ideal resocializador- $y$, en consecuencia, la apertura a nuevos horizontes del poder punitivo, conllevaron a una actualidad en la cual la noción de riesgo atraviesa transversalmente las 
políticas públicas en torno a la seguridad, el funcionamiento de los sistemas penales, y los comportamientos y representaciones de la ciudadanía. Ante este cuadro, surgen interrogantes que abren nuevas líneas de debate e investigación: ¿El modelo de cobertura de la seguridad inspirado en el welfarismo, el cual consiste en extender y garantizar la seguridad del conjunto de la ciudadanía, está en declive en algunos Estados del "norte” global? ¿Y en los Estados del “sur”? En caso de una respuesta afirmativa, ¿qué modelo predomina? El que predomina, ¿se complementa o sustituye al modelo benefactor del welfarismo? En línea con estas reflexiones,

¿la criminología actuarial ha penetrado en la gestión securitaria en los Estados del “sur”?, ¿de qué manera?

\section{Bibliografía}

Arella, C. I., Fernández Bessa, C., Lazo, G. N. y Vartabedian, J. (2005). Una aproximación a la vulneración de los derechos humanos de las trabajadoras sexuales en la ciudad de Barcelona [en línea]. Barcelona: OSPDH. Disponible en:

$\underline{\text { http://pmayobre.webs.uvigo.es/textos/varios/vulneracion.pdf }}$

Ayos, E y Fiuza Casais, P. (2018). (Re)definiendo la cuestión securitaria: tensiones y aperturas en las problematizaciones en torno a una «seguridad democrática» en el período 2000-2015. Delito y Sociedad, 1(45), 57-87.

Baratta, A. (1997). Política Criminal: Entre la Política Social y la Política de Seguridad. En: Carranza, E. (Coord.) Delito y Seguridad de los Habitantes. México, D.F.: Editorial Siglo XXI. Baratta, A. (2001). Seguridad. Capitulo Criminológico, 29(2), 1-24.

Beck, U. [1986] (1998). La Sociedad del Riesgo. Hacia una nueva modernidad. Barcelona: Editorial Paidós Ibérica.

Brandariz García, J. A. (2014). La difusión de las lógicas actuariales y gerenciales en las políticas punitivas. InDret (2), 27-34.

Castel, R. (2005). Michel Foucault et 1'histoire du présent. En: Hatchuel, A. et al. Gouvernement, organisation et gestion: l'héritage de Michel Foucault (pp. 51-61). Québec: Presses de 1'Université de Laval

Crawford, A. (1998). Community safety and the quest for security: Holding back the dynamics of social exclusion. Policy Studies, 19(3-4), 237-253. 
Creazzo, G. (1996). Le politiche di» nuova «prevenzione: lo stato dell'arte. Quaderni di Città sicure, $4,13-28$.

Domínguez Figueirido, J. L. y Rodríguez Basanta, A. (2003). Lógica actuarial, seguridad y sistema de justicia criminal. En: Cándido Da Agra et al. (Eds.) La seguridad en la sociedad del riesgo: Un debate abierto (pp. 329-352). Barcelona: Atelier.

Feeley. M. y Simon, J. (1995). La nueva penología: notas acerca de las estrategias emergentes en el sistema penal y sus implicaciones. Delito y Sociedad, año 4, (6-7), 33-58.

Felson, M. y Clarke, R. (2008). La ocasión hace al ladrón. Teoría práctica para la prevención del delito. Traducción de Maite Díaz i Pont y David Felip i Saborit. Serie Claves del Gobierno Local [en línea], (6), 193-234. Disponible en:

http://repositorio.gobiernolocal.es/xmlui/bitstream/handle/10873/855/claves06_09_felson_clark e.pdf

Floud, J. y Young, W. (1981). Dangerousness and Criminal Justice. London: Heinemann.

Fraile, P. y Bonastra, Q. (2011). Espacio, delincuencia y seguridad: hacia el diseño de un modelo de análisis territorial. Boletín de la Asociación de Geógrafos Españoles, (57), 123-146.

Fraile, P. y Bonastra, Q. (2015). Delito y espacio en ciudades intermedias: afinando un modelo de análisis territorial en Gerona, Tarragona y Lérida. Boletín de la Asociación de Geógrafos Españoles (67), 303-326.

García, S. y Ávila, D. (2015). La prevención securitaria como modo de gobierno: el caso de Madrid. Revista Athenea Digital, 16(1), 43-82.

Garland, D. (2005). La Cultura del Control. Barcelona: Editorial Gedisa.

Greenwood, P.W. (1982). Selective Incapacitation. Santa Monica, CA: Rand.

Gutiérrez, M. (2008). Punitivismo y actuarialismo en la Argentina. Ponencia presentada en V Jornadas de Sociología de la UNLP, La Plata, Argentina.

Harcourt, E. (2007). Against Prediction. Chicago: Univ. of Chicago Press.

Hudson, B. (2003). Justice in the risk society: Challenging and re-affirming "justice” in late modernity. Londres: Sage.

Lea, J. (2004). Delito y Modernidad. México: Editorial Fontamara.

Lefebvre, H. (1973). De lo rural a lo urbano. Barcelona: Península. 
Lefebvre, H. (1976). Espacio y política. El derecho a la ciudad II. Barcelona: Peninsula.

Logan, W. A. (2000). A Study in "Actuarial Justice": Sex Offender Classification Practice and Procedure. Buffalo Criminal Law Review, 3(2), 503-637.

Martínez Lorea, I. (2013). Prólogo: Henri Lefebvre y los espacios de lo posible. En: Lefebvre, H. La producción del espacio (pp. 9-28). Madrid: Capitán Swing.

Mendiola, I. y Brandariz García, J. A. (2015). Espacios y tiempos en las violencias contemporáneas. Revista Athenea Digital, 16(1), 3-8.

Nuñez, A. (2006). Lo que el agua (no) se llevó... Política urbana, Estado del poder, violencia e identidades sociales. Mar del Plata, entre siglos. Tesis Doctoral FLACSO, Sede Académica Argentina, Buenos Aires [en línea]. Disponible en:

https://repositorio.flacsoandes.edu.ec/handle/10469/1036

O’Malley, P. [1992] (2006). Riesgo, neoliberalismo y justicia penal. Buenos Aires: Ad-Hoc.

OSPDH - Observatorio del Sistema Penal y los Derechos Humanos (2009). Construcció del civisme i gestió de la convivencia a l'espai públic de la ciutat de Barcelona. Informe d'investigació. Amb el supor de Fundació Jaume Boffil [en línea]. Barcelona: UB Barcelona. Disponible en: https://www.fbofill.cat/sites/default/files/1602.pdf

Rivera Beiras, I. y Lazo, G. N. (2005). La crisis del welfare y sus repercusiones en la cultura política europea. En: Rivera Beiras, I (Coord.) Politica Criminal y Sistema Penal: viejas y nuevas racionalidades punitivas (pp. 219-254). Barcelona: Anthropos.

Rivera Beiras, I. (2005). Recorridos y posibles formas de la penalidad. Barcelona: Antrophos.

Rivera Beiras, I. (2015). Actuarialismo penitenciario. Su recepción en España. Revista Crítica Penal y Poder, (9), 102-144.

Pavarini, M. (1994). I Nuovi Confini della Penalità. Bologna: Editoriale Martina.

Pratt, J. (2000). The return of the wheelbarrow men; or, the arrival of postmodern penality? British Journal of Criminology, 40(1), 127-145.

Segato, L. (2007). Los mapas de criminalidad. Congreso Internacional de Ciudades, Urbanismo y Seguridad, 143-175 [en línea]. Disponible en:

https://www.madrid.es/UnidadWeb/Contenidos/Publicaciones/TemaEmergencias/PonenciasCo ngresoCiudades/Ficheros/Parte2.2.pdf 
Sibley, D. (1995). Geographies of Exclusion. Londres: Routledge.

Sozzo, M. (2000). Seguridad Urbana y Tácticas de Prevención del Delito. Cuadernos de jurisprudencia y Doctrina Penal, 10, 17-82.

Summers, L. (2009). Las técnicas de prevención situacional del delito aplicadas a la delincuencia juvenil. Revista de derecho penal y criminología, (1), 395-409. 